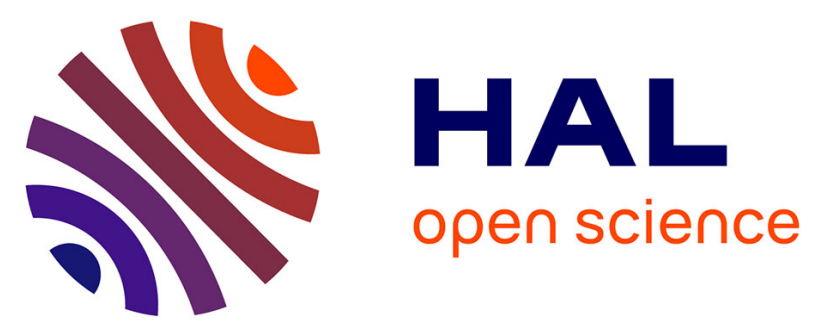

\title{
Venlafaxine versus clonidine for the treatment of hot flashes in breast cancer patients: a double-blind, randomized cross-over study
}

Ciska Buijs, Constantijne H. Mom, Pax H. B. Willemse, H. Marike Boezen, J.

Marina Maurer, A. N. Machteld Wymenga, Robert S. Jong, Peter Nieboer, Elisabeth G. E. Vries, Marian J. E. Mourits

\section{To cite this version:}

Ciska Buijs, Constantijne H. Mom, Pax H. B. Willemse, H. Marike Boezen, J. Marina Maurer, et al.. Venlafaxine versus clonidine for the treatment of hot flashes in breast cancer patients: a double-blind, randomized cross-over study. Breast Cancer Research and Treatment, 2008, 115 (3), pp.573-580. 10.1007/s10549-008-0138-7 . hal-00478254

\section{HAL Id: hal-00478254 https://hal.science/hal-00478254}

Submitted on 30 Apr 2010

HAL is a multi-disciplinary open access archive for the deposit and dissemination of scientific research documents, whether they are published or not. The documents may come from teaching and research institutions in France or abroad, or from public or private research centers.
L'archive ouverte pluridisciplinaire HAL, est destinée au dépôt et à la diffusion de documents scientifiques de niveau recherche, publiés ou non, émanant des établissements d'enseignement et de recherche français ou étrangers, des laboratoires publics ou privés. 


\title{
Venlafaxine versus clonidine for the treatment of hot flashes in breast cancer patients: a double-blind, randomized cross-over study
}

\author{
Ciska Buijs - Constantijne H. Mom • Pax H. B. Willemse $\cdot$ H. Marike Boezen • \\ J. Marina Maurer · A. N. Machteld Wymenga - Robert S. de Jong • \\ Peter Nieboer · Elisabeth G. E. de Vries · Marian J. E. Mourits
}

Received: 12 July 2008/Accepted: 14 July 2008/Published online: 1 August 2008

(C) Springer Science+Business Media, LLC. 2008

\begin{abstract}
Purpose Breast cancer patients with treatmentinduced menopause experience frequent and severe hot flashes (HF). We compared venlafaxine and clonidine for the treatment of HF with regard to side effects, efficacy, quality of life and sexual functioning. Methods In a double-blind, cross-over study, 60 breast cancer patients experiencing $\mathrm{HF}$ were randomized to 8 weeks venlafaxine followed by
\end{abstract}

C. Buijs and C. H. Mom have contributed equally.

C. Buijs · C. H. Mom · P. H. B. Willemse ·

A. N. M. Wymenga · R. S. de Jong · P. Nieboer .

E. G. E. de Vries

Department of Medical Oncology, University Medical Center

Groningen, University of Groningen, Groningen,

The Netherlands

C. H. Mom $(\bowtie) \cdot$ M. J. E. Mourits

Department of Gynecologic Oncology, University Medical Center Groningen, University of Groningen, P.O. Box 30.001, Groningen 9700 RB, The Netherlands

e-mail: c.h.mom@og.umcg.nl

H. Marike Boezen

Department of Epidemiology, University Medical Center

Groningen, University of Groningen, Groningen,

The Netherlands

J. M. Maurer

Hospital Pharmacy, University Medical Center

Groningen, University of Groningen, Groningen,

The Netherlands

A. N. M. Wymenga

Medical Spectrum Twente, Enschede, The Netherlands

R. S. de Jong

Martini Hospital, Groningen, The Netherlands

P. Nieboer

Wilhelmina Hospital, Assen, The Netherlands
2 weeks wash-out, and 8 weeks clonidine or vice versa. HF frequency and severity, side effects, quality of life and sexuality were assessed. Results Thirty patients started with venlafaxine and 30 with clonidine. Premature discontinuation for toxicity occurred in 14/59 during venlafaxine and 5/ 53 during clonidine $(P=.038)$. Venlafaxine induced more side effects. Median reduction in HF score was $49 \%$ for venlafaxine and 55\% for clonidine (ns). Conclusion Venlafaxine and clonidine are equally, but moderately effective in $\mathrm{HF}$ reduction. Side effects are the main reason for drug discontinuation, occurring more often with venlafaxine.

Keywords Breast cancer - Hot flashes - Menopause · Clonidine $\cdot$ Venlafaxine

\section{Introduction}

Hot flashes, commonly experienced by post- and premenopausal women, are often bothersome and can have a negative influence on quality of life $[1,2]$. Women treated for breast cancer experience more frequent and more severe hot flashes than healthy women $[3,4]$. This is partly due to the acute onset of menopause in breast cancer patients resulting from ovarian ablation caused by chemotherapy, surgery or luteinizing hormone-releasing hormone (LHRH) analogues [3, 5-7]. Moreover, adjuvant endocrine treatment with tamoxifen or aromatase inhibitors is associated with vasomotor instability [4]. As a growing number of women receive adjuvant therapy for breast cancer, and as more women survive breast cancer nowadays, treatment of hot flashes is increasingly important.

In healthy postmenopausal women, therapy with estrogens is very effective in reducing hot flashes. However, significant increases in the risk of cardiovascular events 
and breast cancer have recently been associated with hormone replacement therapy $[8,9]$. In women with a history of breast cancer hormonal therapy should be avoided, because of possible stimulating effects on tumor growth [8]. Drugs that do not interfere with steroid receptors, among which clonidine and venlafaxine, are efficacious in reducing hot flashes in breast cancer patients in randomized placebo-controlled trials [10-12].

Clonidine is a centrally acting $\alpha$-adrenergic agonist, that alleviates hot flashes at an oral dose of $0.05 \mathrm{mg}$ twice daily (bid) $[11,13,14]$. Venlafaxine, a combined serotonin and norepinephrine re-uptake inhibitor (SNRI), is effective for the reduction of hot flashes in a dose of $75 \mathrm{mg}$ once daily (od) as extended-release formulation $[12,15,16]$. In most studies, venlafaxine was tested for this indication for 4 weeks, which may be too short for an evaluation of longterm side effects. Venlafaxine and clonidine both have their own side effect profile, but the tolerability of these drugs for a longer time period, as well as their influence on quality of life, is still largely unknown.

This double-blind, randomized, cross-over study in breast cancer patients was primarily designed to compare side effects of venlafaxine and clonidine, both administered for an 8-week period. Secondary objectives were to evaluate efficacy and the influences of both drugs on quality of life and sexual functioning.

\section{Materials and methods}

\section{Patients}

Eligible for this trial were patients with primary or metastatic breast cancer, aged $\leq 60$ years, and experiencing $\geq 14$ hot flashes/week. Patients were allowed hormonal antitumor treatment, including tamoxifen, aromatase inhibitors and LHRH analogues, if started at least a month before entry and scheduled to continue throughout the study. Adequate liver and kidney functions, a life expectancy of $\geq 6$ months, and an ECOG performance status of $0-1$ were required. Women were not eligible if they had previously used venlafaxine or clonidine, had received other treatment for hot flashes within the previous month, or were treated with a B-blocker, sedatives or antidepressants.

All patients gave written informed consent. The study was approved by the Ethical Committees of the participating centers.

\section{Medication}

Patients were randomly assigned to receive venlafaxine for 8 weeks, followed by 2 weeks wash-out and 8 weeks of clonidine, or vice versa. Patients received either $75 \mathrm{mg}$ venlafaxine extended-release od (Efexor, Wyeth, Madison, $\mathrm{NJ}$ ) or $0.05 \mathrm{mg}$ clonidine bid (Centrafarm, Etten-Leur,
Netherlands). To ensure the double-blind execution of the trial, placebo tablets with identical appearance to clonidine were administered along with over-encapsulated capsules of venlafaxine, and identical looking placebo capsules of "venlafaxine" accompanied clonidine. Randomization, packaging and labeling of the medication was performed by the pharmacy department of the UMCG.

Study medication was discontinued for unacceptable side effects or at the patient's request. No dose modifications were allowed. At the last study visit, patients could indicate whether they wished to continue their drug of preference. The attending doctor received the name of the drug from the hospital pharmacist. This information was not available to the study coordinator.

Frequency of outpatient visits

Patients visited the outpatient clinic at study entry and 2, 8, 12 and 18 weeks thereafter. Assessments took place before the start of each drug, after 2 weeks for evaluation of acute toxicity and short-term effects, and after 8 weeks, at the end of each treatment period. Medical history and sociodemographic information were obtained at baseline. Blood pressure was measured each visit.

\section{Questionnaires}

Six questionnaires were used to compare the drugs in terms of side effects, efficacy, quality of life and sexual functioning before start of each treatment period (baseline), and after 2 and 8 weeks of treatment in both periods.

The questionnaires are described below:

\section{Questionnaire on adverse events}

This questionnaire contained a list of known side effects of both drugs and free space to specify other symptoms. Severity of these symptoms was assessed on a 4-point Likert scale, ranging from "not at all" to "very bothersome".

\section{Daily diary on hot flashes}

In the diary patients scored the frequency and severity (mild: 1 point, moderate: 2 , severe: 3 , and very severe: 4 points) of hot flashes for seven days at baseline and in week 2 (days 8-14) and week 8 (days 50-56) of each treatment period. Hot flash scores were calculated by multiplying the number of hot flashes with their severity $[11,17,18]$.

\section{Hot flash related daily interference questionnaire}

Patients indicated on a 10-point scale ( 0 : no interference, to 10: complete interference) the impact of hot flashes on 10 
variables: work, social activities, leisure activities, sleep, mood, concentration, relationships with others, sexuality, pleasure in life and quality of life as a whole [19]. Hot Flash Related Daily Interference Scores (HFRDIS) were computed by summing up the scores of the variables (0-100).

\section{Medical outcomes study short form-36 (SF-36)}

This questionnaire was used to assess the influence of hot flashes and treatment on quality of life [20]. The SF-36 comprises physical functioning, role-physical, pain, general health, vitality, social functioning, role-emotional and mental health. The scores ranged from 0 to 100 , with higher scores reflecting a higher level of functioning.

\section{Sexual activity questionnaire (SAQ)}

The SAQ was used to measure impact of treatment on sexual functioning [21]. The questionnaire investigated whether a woman was sexually active, and if not, reasons for sexual inactivity. In sexually active patients pleasure, discomfort and habits in sexual functioning were evaluated using a 4-point scale.

\section{Zung self-rating depression scale}

The Zung Self-rating Depression Scale consists of 20 items, each item relating to a specific characteristic of depression [22]. Respondents indicated on a 4-point rating scale (from seldom/never to almost always) the extent to which a statement applied to them. The total score referred to a state within the normal boundaries or depression (ranging from minimal to very severe).

\section{Statistics}

The study was powered for differences in side effects, e.g. mouth dryness has an incidence of $22 \%$ in patients using venlafaxine and of $40 \%$ in patients using clonidine. Assuming that $90 \%$ to $95 \%$ of the dry mouth events in patients receiving venlafaxine would also occur with clonidine, using McNemar's test, power $85 \%$ and $P=.05$ (2sided), 48 patients were needed to detect a difference. Similar patient numbers would have been needed if these calculations were made for other side effects. In their studies, the North Central Cancer Treatment Group (NCCTG) found completion rates of $90 \%$ for the Daily Diary on Hot Flashes [23]. Taking into account a potential $10 \%$ study drop out, 60 patients were needed to find significant differences.

Data were analyzed according to intention-to-treat principle. The incidence rates of side effects were compared by McNemar's test. Differences in hot flash frequency and scores were tested using Wilcoxon SignedRank Test. The paired sample $t$-test was used for parametric variables. $P<.05$ (2-sided) were considered significant.

\section{Results}

Patients

Between October 2003 and May 2006, 60 patients were enrolled. Baseline patient characteristics were well balanced between both treatment sequences (Table 1). The flow chart of study accrual and retention is depicted in Fig. 1. Forty patients completed both periods, 12 patients only one period (venlafaxine: $n=4$, clonidine: $n=8$ ) and 8 patients neither. During venlafaxine treatment 15 out of 59 patients withdrew, whereas 5 out of 53 patients stopped clonidine $(P=.038)$. Withdrawal rates were not affected by the sequence in which the drugs were given. Reasons for premature discontinuation were side effects in all but one of the patients, who withdrew from venlafaxine because of tumor progression. Five patients prematurely stopped venlafaxine in the first period and declined clonidine. One

Table 1 Patient characteristics at baseline $(n=60)$

\begin{tabular}{|c|c|c|}
\hline \multirow[t]{2}{*}{ Characteristic } & \multicolumn{2}{|c|}{ No. of patients } \\
\hline & $\begin{array}{l}\text { Venlafaxine/ } \\
\text { clonidine }\end{array}$ & $\begin{array}{l}\text { Clonidine/ } \\
\text { venlafaxine }\end{array}$ \\
\hline \multicolumn{3}{|l|}{ Age (years) } \\
\hline Median (range) & $49(39-59)$ & $51(35-60)$ \\
\hline \multicolumn{3}{|l|}{ Duration of hot flashes } \\
\hline$\leq 9$ months & 2 & 3 \\
\hline$>9$ months & 28 & 27 \\
\hline \multicolumn{3}{|l|}{ Prior chemotherapy } \\
\hline Yes & 26 & 24 \\
\hline No & 3 & 6 \\
\hline Unknown & 1 & 0 \\
\hline \multicolumn{3}{|l|}{ Prior radiation therapy } \\
\hline Yes & 23 & 19 \\
\hline No & 7 & 11 \\
\hline \multicolumn{3}{|l|}{ Current endocrine therapy } \\
\hline Tamoxifen & 16 & 14 \\
\hline Tamoxifen and LHRH analogue & 1 & 3 \\
\hline LHRH analogue & 2 & 0 \\
\hline Aromatase inhibitor & 7 & 3 \\
\hline Aromatase inhibitor and LHRH analogue & 0 & 2 \\
\hline None & 4 & 8 \\
\hline
\end{tabular}

Abbreviation: LHRH, luteinizing hormone-releasing hormone 


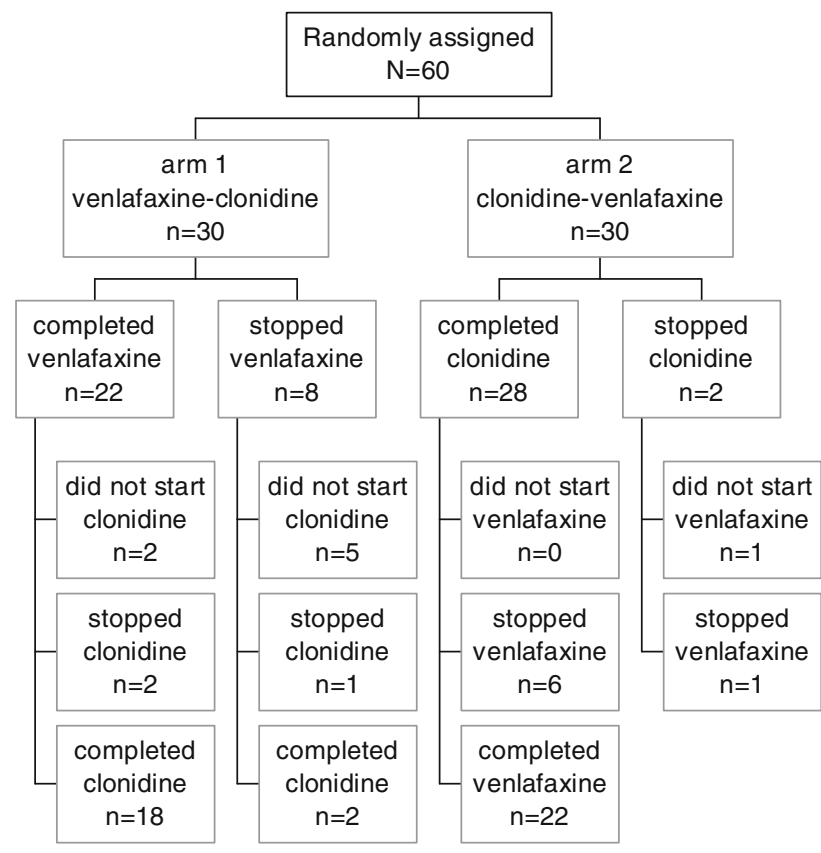

Fig. 1 Flow diagram and retention of the patients on study

patient who discontinued clonidine also refused to crossover.

\section{Adverse events}

Baseline symptoms and subsequent side effects are presented in Table 2.

The most frequent reasons for premature discontinuation of venlafaxine in 14 patients were nausea $(n=11)$, headache $(n=8)$, dizziness $(n=4)$ and mood disorders $(n=4)$. Eight stopped within 5 days, the others after 2 weeks. After 2 weeks 5 patients prematurely stopped clonidine, with dry mouth as the most frequently mentioned cause for discontinuation. Compared to baseline, more patients on venlafaxine reported nausea, headache, dizziness, taste alteration, decreased appetite and constipation after 2 weeks. Improvement was observed with regard to sleep and sexual interest. For clonidine there was no difference in symptoms compared to baseline.

When venlafaxine is compared to clonidine after 2 weeks, more patients reported taste alteration, appetite loss, nausea and constipation with venlafaxine, whereas pain and itching were more often seen with clonidine.

Compared to baseline, improved sleep was more frequently observed after 8 weeks of venlafaxine and improved sexual interest after 8 weeks of clonidine. When both drugs are compared in week 8 , more patients on venlafaxine noticed appetite loss, while disturbed sleep was more often seen with clonidine. On venlafaxine patients reported less symptoms after 8 than after 2 weeks.
Blood pressure was not affected by venlafaxine. Clonidine caused small absolute decreases in both systolic $(5 \mathrm{mmHg}) \quad(P=.014)$ and diastolic blood pressure $(3 \mathrm{mmHg})(P=.012)$ after 8 weeks.

Efficacy

Changes in hot flash frequency are demonstrated in Fig. 2 and the residual hot flash score after 8 weeks is shown in Table 3. With both drugs the hot flash scores were reduced with a median of $49 \%$ for venlafaxine and $55 \%$ for clonidine after 8 weeks. No difference in hot flash reduction was seen between the two drugs $(P=.55)$. A complete disappearance of hot flashes was seen in 4 patients during venlafaxine, but not on clonidine. Increased hot flash scores were observed in 11 patients during venlafaxine and in 6 patients during clonidine. Fifty percent of the patients on venlafaxine and 55\% of the patients on clonidine reported a $\geq 50 \%$ reduction in hot flash score after 8 weeks.

In patients who completed both treatment periods, a $\geq 50 \%$ reduction in hot flash score was found on both drugs in $21 \%$, on clonidine alone in $32 \%$, on venlafaxine alone in $29 \%$ and on none of the drugs in $18 \%$. Of all 60 patients included, $65 \%$ of the patients showed $\mathrm{a} \geq 50 \%$ reduction on one or both drugs. The drug that patients received first caused the greatest reduction in hot flash score (median decrease of $63 \%$ vs. $28 \%, P=.03$ ).

Interference of hot flashes with daily life

Mean baseline scores were similar in both groups. The mean HFRDIS decreased from 31 to 18 in week 8 of venlafaxine $(P=.001)$ and from 37 to 21 in week 8 of clonidine $(P<.001)$, indicating less interference of hot flashes with daily life. Of the HFRDIS items, sleep was particularly affected by hot flashes. Nine HFRDIS items showed an improvement in week 8, independent of the drug taken and without differences between both drugs. Less interference of hot flashes with sexuality was observed only with clonidine, not with venlafaxine.

Medical outcomes study short form-36 (SF-36)

Table 4 shows the SF-36 outcomes after 8 weeks. Only role-emotional showed amelioration with venlafaxine and role-physical with clonidine. No differences in subscale scores between the drugs were seen.

The 21 patients that experienced $\mathrm{a} \geq 50 \%$ reduction in hot flash score after 8 weeks of venlafaxine perceived an improved mental health, physical functioning, social functioning, and role-physical. Patients $(\mathrm{n}=26)$ with $\mathrm{a} \geq 50 \%$ reduction on clonidine demonstrated only an 
Table 2 Frequency of side effects at baseline, week 2 and 8

\begin{tabular}{|c|c|c|c|c|c|c|c|c|c|c|}
\hline & \multicolumn{5}{|l|}{ Venlafaxine } & \multicolumn{5}{|c|}{ Clonidine } \\
\hline & \multirow{2}{*}{$\begin{array}{l}\text { Baseline }(n=60) \\
\%\end{array}$} & \multicolumn{2}{|c|}{ Week $2(n=53)$} & \multicolumn{2}{|c|}{ Week $8(n=44)$} & \multicolumn{2}{|c|}{ Week $2(n=53)$} & \multicolumn{3}{|c|}{ Week $8(n=48)$} \\
\hline & & $\%$ & $P^{\mathrm{a}}$ & $\%$ & $P^{\mathrm{a}}$ & $\%$ & $P^{\mathrm{b}}$ & $\%$ & $P^{\mathrm{a}}$ & $P^{\mathrm{c}}$ \\
\hline Nausea & 12 & 47 & $<.001$ & 19 & & 11 & $<.001$ & 23 & & \\
\hline Constipation & 30 & 49 & .012 & 31 & & 32 & .021 & 26 & & \\
\hline Diarrhea & 13 & 11 & & 5 & & 15 & & 9 & & \\
\hline Vomiting & 2 & 8 & & 5 & & 2 & & 0 & & \\
\hline Appetite loss & 13 & 38 & $<.001$ & 24 & & 13 & .006 & 4 & & .031 \\
\hline Abdominal pain & 15 & 17 & & 17 & & 19 & & 11 & & \\
\hline Taste alteration & 7 & 21 & .008 & 10 & & 6 & .016 & 9 & & \\
\hline Dry mouth & 55 & 60 & & 55 & & 64 & & 47 & & \\
\hline Dizziness & 30 & 43 & .011 & 24 & & 32 & & 32 & & \\
\hline Headache & 45 & 53 & .012 & 38 & & 49 & & 43 & & \\
\hline Fatigue & 88 & 87 & & 74 & & 87 & & 85 & & \\
\hline Insomnia & 72 & 74 & & 55 & & 64 & & 57 & & \\
\hline Abnormal dreaming & 13 & 19 & & 33 & & 17 & & 19 & & \\
\hline Sleep disturbance & 85 & 62 & .022 & 55 & .021 & 81 & & 75 & & .039 \\
\hline Sweating & 97 & 92 & & 91 & & 91 & & 94 & & \\
\hline Skin problems & 15 & 11 & & 10 & & 15 & & 17 & & \\
\hline Itching & 27 & 11 & & 12 & & 19 & .031 & 24 & & \\
\hline Decreased sexual interest & 68 & 53 & .008 & 51 & & 53 & & 46 & .035 & \\
\hline Pain & 57 & 42 & & 43 & & 59 & .039 & 45 & & \\
\hline Fear & 25 & 11 & & 12 & & 15 & & 11 & & \\
\hline Nervousness & 30 & 28 & & 21 & & 30 & & 32 & & \\
\hline Restlessness & 50 & 42 & & 33 & & 47 & & 36 & & \\
\hline Paresthesia & 35 & 42 & & 17 & & 32 & & 23 & & \\
\hline
\end{tabular}

${ }^{a}$ Frequency of symptoms compared to baseline

${ }^{\mathrm{b}}$ Frequency of symptoms in week 2 of venlafaxine compared to week 2 of clonidine

${ }^{c}$ Frequency of symptoms in week 8 of venlafaxine compared to week 8 of clonidine

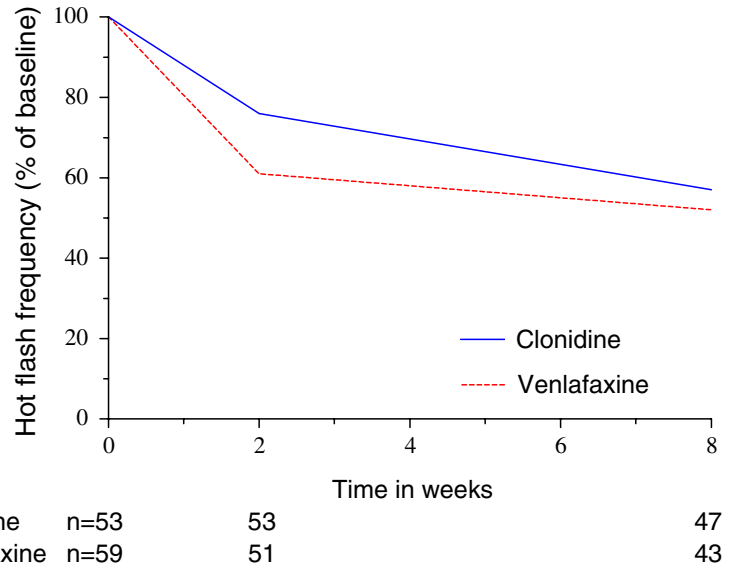

Fig. 2 Changes in hot flash frequency from baseline for venlafaxine and clonidine $(\%)$

improved vitality score. Mean scores in these subgroups increased from 8 to 14 points, which is a clinically meaningful improvement.
Table 3 Change in hot flash score from baseline to week 8

\begin{tabular}{lcrlrr}
\hline \% of Baseline score & \multicolumn{2}{l}{ Venlafaxine $(n=43)$} & & \multicolumn{2}{c}{ Clonidine $(n=47)$} \\
\cline { 2 - 3 } & No. of patients & $\%$ & & No. of patients & $\%$ \\
\hline 0 & 4 & 9 & 0 & 0 \\
$1-24$ & 8 & 19 & 10 & 21 \\
$25-49$ & 9 & 21 & 15 & 32 \\
$50-74$ & 7 & 16 & 12 & 25 \\
$75-100$ & 4 & 9 & 4 & 9 \\
$>100$ & 11 & 26 & 6 & 13 \\
\hline
\end{tabular}

Sexual activity

Thirty-three patients were sexually active. The most common reasons reported for sexual inactivity were lack of sexual interest, lack of sexual interest of the partner and tiredness. No effects of venlafaxine or clonidine on the SAQ scales were found. 
Table 4 Outcomes of the 8 subscales of the SF-36 for all patients and those with good response ( $\geq 50 \%$ reduction in hot flash scores) in week 8

\begin{tabular}{|c|c|c|c|c|c|}
\hline & \multirow{2}{*}{$\begin{array}{l}\text { Baseline } \\
(n=60)\end{array}$} & \multicolumn{2}{|c|}{ Venlafaxine } & \multicolumn{2}{|l|}{ Clonidine } \\
\hline & & $\begin{array}{l}\text { Total } \\
(n=44)\end{array}$ & $\begin{array}{l}\text { Patients } \geq 50 \% \text { reduction } \\
(n=21)\end{array}$ & $\begin{array}{l}\text { Total } \\
(n=48)\end{array}$ & $\begin{array}{l}\text { Patients } \geq 50 \% \text { reduction } \\
(n=26)\end{array}$ \\
\hline Physical functioning & 75 & 79 & $86^{*}$ & 78 & 79 \\
\hline Social functioning & 83 & 86 & $89 *$ & 86 & 86 \\
\hline Role-physical & 58 & 77 & $85^{*}$ & $75^{*}$ & 70 \\
\hline Role-emotional & 80 & $94 *$ & 94 & 86 & 84 \\
\hline Bodily pain & 72 & 81 & 83 & 77 & 77 \\
\hline Vitality & 61 & 60 & 59 & 56 & $83^{*}$ \\
\hline Mental health & 79 & 82 & $86^{*}$ & 78 & 79 \\
\hline General health & 66 & 71 & 74 & 67 & 62 \\
\hline
\end{tabular}

The subscales scores range from 0 to 100 , with higher scores representing a higher level of functioning

* Subscale scores compared to baseline $P<.05$

Zung self-rating depression score

After 8 weeks of venlafaxine the mean Zung score improved from 45.7 to $40.7(P=.001)$. No change in mean Zung score was seen after 8 weeks of clonidine.

\section{Patient preference}

When asked for their preference at the end of the study, 20 patients $(33 \%)$ indicated they wished to continue clonidine, $17(29 \%)$ preferred venlafaxine, and 23 (38\%) did not want to continue either treatment (ns).

\section{Discussion}

Although several studies have evaluated the efficacy and side effects of venlafaxine and clonidine, this is the first double-blind, randomized, cross-over study that directly compared venlafaxine and clonidine for 8 weeks. We found that venlafaxine caused significantly more side effects during the first weeks of treatment, and that more patients discontinued venlafaxine for this reason. After 8 weeks of treatment however, both drugs were well tolerated and were equally efficacious, with a median decrease in hot flash score of $49 \%$ for venlafaxine and $55 \%$ for clonidine.

We compared both drugs in a randomized cross-over design, because this allowed for analysis of treatment effects with each patient as her own control. To reduce the risk of a carry-over effect, a 2-week wash-out period between the treatment periods was incorporated. In a recent, randomized study, Loibl et al compared venlafaxine with clonidine for 4 weeks [24]. Although a cross-over study was intended, this plan was abandoned due to a high frequency of premature discontinuation and poor reporting.
Most studies evaluated the effects of venlafaxine for 4 weeks [11, 12, 24]. However, this may be too short for assessing longer-term toxicity and the impact of hot flash reduction on quality of life and sexual functioning. A placebo-controlled trial of venlafaxine for 12 weeks was performed in healthy postmenopausal women, but in this study no baseline data on symptoms were available [25]. Recently, a study in breast cancer patients was performed comparing venlafaxine with placebo for 6 weeks [10]. After the study, patients could continue venlafaxine and were contacted after 1, 6 and 12 months. Although side effects with venlafaxine were mild during the first 6 treatment weeks, they were a main reason for discontinuation of venlafaxine in the long-term. Thus, side effects are important for prolonged use of medication, especially when treatment effects are modest. We therefore administered both drugs for 8 weeks.

Patient accrual proceeded slower than expected. This was due to reluctance of patients to use medication for their hot flashes and due to antidepressant, sedative or antihypertensive use, which made patients ineligible because of possible interactions with the study drugs.

During the first treatment weeks, we observed more side effects with venlafaxine, including nausea, constipation, taste alteration and appetite loss. The optimal venlafaxine dose to alleviate hot flashes is $75 \mathrm{mg}$ od, which is also the recommended starting dose for depression [12]. However, initial side effects may be reduced if a starting dose of $37.5 \mathrm{mg}$ od is used for one week, followed by $75 \mathrm{mg}$ od. Patients on clonidine reported more pain and itching after 2 weeks. At the end of the 8-week treatment periods less toxicity was reported, indicating that most side effects resolved with time. Only appetite loss was still frequently seen with venlafaxine. Some groups report increased mouth dryness with venlafaxine [12, 25] and clonidine $[11,14]$, while we observed no increases. This may be due 
to the high frequency at baseline (55\% of the patients). Nevertheless, mouth dryness was the primary reason for discontinuation of clonidine in 3 patients. Sleep difficulties are also a commonly mentioned side effect in some studies with clonidine [14] and venlafaxine [25]. In agreement with Carpenter et al, we saw the opposite effect [10]. Patients reported improved sleep with venlafaxine, which may result from a reduction of hot flashes during the night.

In the study by Loibl et al, 33 breast cancer patients received clonidine and 31 venlafaxine for 4 weeks [24]. Venlafaxine was marginally more effective than clonidine, with reductions in hot flash scores of respectively $57 \%$ and $39 \%(P=.043)$. In contrast to their study, we did not find superiority of one drug over the other. This is consistent with our observation that patients had no explicit preference for one drug.

Hot flashes are a prominent side effect of tamoxifen and aromatase inhibitors. Early discontinuation rates of tamoxifen range from $15 \%$ to $35 \%$, resulting in higher breast cancer recurrence rates and mortality [26]. Patients reporting side effects are more likely to stop tamoxifen prematurely [27-29] Therefore, the development of strategies to circumvent these side effects is important, as they may increase therapy adherence.

Quality of life and sexuality were secondary outcome measures. The improvement of aspects of quality of life in patients reporting a $\geq 50 \%$ reduction in hot flash score may indicate that quality of life is only enhanced, when patients experience a substantial treatment effect. However, patients on venlafaxine improved on more subscales than patients on clonidine, which may also indicate a direct influence of venlafaxine on quality of life.

Hot flashes appear to negatively influence sexuality [3] and in addition sexual dysfunction is a known side effect of SSRIs [30, 31]. Patients on clonidine reported increased sexual interest and less interference of hot flashes with sexuality. However, we found no effect on sexual functioning with clonidine. Venlafaxine did not affect sexual functioning either.

SSRIs interfere with tamoxifen metabolism by inhibiting cytochrome P450 2D6 (CYP2D6), resulting in lower concentrations of endoxifen, the most active tamoxifen metabolite [32]. As venlafaxine is a weak inhibitor of CYP2D6 and only slightly reduces plasma endoxifen levels, it is currently the best SSRI/SNRI option for the treatment of hot flashes.

\section{Conclusion}

This study demonstrates that although venlafaxine and clonidine have different side effects, they are well tolerated with similar efficacy. Two thirds of the patients showed a $\geq 50 \%$ reduction on one or both drugs. When making treatment choices for hot flashes in individual patients, side effects and possible interactions with other drugs should be taken into account. In breast cancer patients venlafaxine and clonidine are equally good alternatives for the prevention of hot flashes.

\section{References}

1. Mourits MJ, Bockermann I, De Vries EG et al (2002) Tamoxifen effects on subjective and psychosexual well-being, in a randomised breast cancer study comparing high-dose and standarddose chemotherapy. Br J Cancer 86:1546-1550. doi:10.1038/ sj.bjc. 6600294

2. Stein KD, Jacobsen PB, Hann DM et al (2000) Impact of hot flashes on quality of life among postmenopausal women being treated for breast cancer. J Pain Symptom Manage 19:436-445. doi:10.1016/S0885-3924(00)00142-1

3. Carpenter JS, Andrykowski MA, Cordova M et al (1998) Hot flashes in postmenopausal women treated for breast carcinoma: prevalence, severity, correlates, management, and relation to quality of life. Cancer 82:1682-1691. doi:10.1002/(SICI)10970142(19980501)82:9<1682::AID-CNCR14>3.0.CO;2-0

4. Couzi RJ, Helzlsouer KJ, Fetting JH (1995) Prevalence of menopausal symptoms among women with a history of breast cancer and attitudes toward estrogen replacement therapy. J Clin Oncol 13:2737-2744

5. Loprinzi CL, Barton DL, Rhodes D (2001) Management of hot flashes in breast-cancer survivors. Lancet Oncol 2:199-204. doi: 10.1016/S1470-2045(00)00289-8

6. Nystedt M, Berglund G, Bolund C et al (2000) Randomized trial of adjuvant tamoxifen and/or goserelin in premenopausal breast cancer-self-rated physiological effects and symptoms. Acta Oncol 39:959-968. doi:10.1080/02841860050215945

7. Bines J, Oleske DM, Cobleigh MA (1996) Ovarian function in premenopausal women treated with adjuvant chemotherapy for breast cancer. J Clin Oncol 14:1718-1729

8. Beral V (2003) Breast cancer and hormone-replacement therapy in the Million Women Study. Lancet 362:419-427. doi:10.1016/ S0140-6736(03)14596-5

9. Rossouw JE, Anderson GL, Prentice RL et al (2002) Risks and benefits of estrogen plus progestin in healthy postmenopausal women: principal results from the Women's Health Initiative randomized controlled trial. JAMA 288:321-333. doi:10.1001/ jama.288.3.321

10. Carpenter JS, Storniolo AM, Johns S et al (2007) Randomized, double-blind, placebo-controlled crossover trials of venlafaxine for hot flashes after breast cancer. Oncologist 12:124-135. doi: 10.1634/theoncologist.12-1-124

11. Goldberg RM, Loprinzi CL, O'Fallon JR et al (1994) Transdermal clonidine for ameliorating tamoxifen-induced hot flashes. $\mathrm{J}$ Clin Oncol 12:155-158

12. Loprinzi CL, Kugler JW, Sloan JA et al (2000) Venlafaxine in management of hot flashes in survivors of breast cancer: a randomised controlled trial. Lancet 356:2059-2063. doi: 10.1016/S0140-6736(00)03403-6

13. Laufer LR, Erlik Y, Meldrum DR et al (1982) Effect of clonidine on hot flashes in postmenopausal women. Obstet Gynecol 60:583-586

14. Pandya KJ, Raubertas RF, Flynn PJ et al (2000) Oral clonidine in postmenopausal patients with breast cancer experiencing tamoxifen-induced hot flashes: a University of Rochester Cancer Center Community Clinical Oncology Program study. Ann Intern Med 132:788-793

15. Barton D, La VB, Loprinzi C et al (2002) Venlafaxine for the control of hot flashes: results of a longitudinal continuation study. Oncol Nurs Forum 29:33-40. doi:10.1188/02.ONF.33-40 
16. Loprinzi CL, Pisansky TM, Fonseca R et al (1998) Pilot evaluation of venlafaxine hydrochloride for the therapy of hot flashes in cancer survivors. J Clin Oncol 16:2377-2381

17. Barton DL, Loprinzi CL, Quella SK et al (1998) Prospective evaluation of vitamin $\mathrm{E}$ for hot flashes in breast cancer survivors. J Clin Oncol 16:495-500

18. Loprinzi CL, Michalak JC, Quella SK et al (1994) Megestrol acetate for the prevention of hot flashes. N Engl J Med 331: 347-352. doi:10.1056/NEJM199408113310602

19. Carpenter JS, Johnson D, Wagner L et al (2002) Hot flashes and related outcomes in breast cancer survivors and matched comparison women. Oncol Nurs Forum 29:E16-E25. doi:10.1188/ 02.ONF.E16-E25

20. Ware JE, Snow KK, Kosinski M et al (2000) SF-36 Health Survey: Manual and Interpretation Guide. QualityMetric Incorporated, Lincoln

21. Thirlaway K, Fallowfield L, Cuzick J (1996) The sexual activity questionnaire: a measure of women's sexual functioning. Qual Life Res 5:81-90. doi:10.1007/BF00435972

22. Zung WW (1965) A self-rating depression scale. Arch Gen Psychiatry 12:63-70

23. Sloan JA, Loprinzi CL, Novotny PJ et al (2001) Methodologic lessons learned from hot flash studies. J Clin Oncol 19:4280-4290

24. Loibl S, Schwedler K, von MG et al (2007) Venlafaxine is superior to clonidine as treatment of hot flashes in breast cancer patients- a double-blind, randomized study. Ann Oncol 18: 689-693. doi:10.1093/annonc/mdl478
25. Evans ML, Pritts E, Vittinghoff E et al (2005) Management of postmenopausal hot flushes with venlafaxine hydrochloride: a randomized, controlled trial. Obstet Gynecol 105:161-166

26. Group Early Breast Cancer Trialists' Collaborative (1998) Tamoxifen for early breast cancer: an overview of the randomised trials. Lancet 351:1451-1467. doi:10.1016/S0140-6736(97) 11423-4

27. Barron TI, Connolly R, Bennett K et al (2007) Early discontinuation of tamoxifen: a lesson for oncologists. Cancer 109:832839. doi: $10.1002 / \mathrm{cncr} .22485$

28. Demissie S, Silliman RA, Lash TL (2001) Adjuvant tamoxifen: predictors of use, side effects, and discontinuation in older women. J Clin Oncol 19:322-328

29. Lash TL, Fox MP, Westrup JL et al (2006) Adherence to tamoxifen over the five-year course. Breast Cancer Res Treat 99:215-220. doi:10.1007/s10549-006-9193-0

30. Keltner NL, McAfee KM, Taylor CL (2002) Mechanisms and treatments of SSRI-induced sexual dysfunction. Perspect Psychiatr Care 38:111-116

31. Montejo-Gonzalez AL, Llorca G, Izquierdo JA et al (1997) SSRIinduced sexual dysfunction: fluoxetine, paroxetine, sertraline, and fluvoxamine in a prospective, multicenter, and descriptive clinical study of 344 patients. J Sex Marital Ther 23:176-194

32. Jin Y, Desta Z, Stearns V et al (2005) CYP2D6 genotype, antidepressant use, and tamoxifen metabolism during adjuvant breast cancer treatment. J Natl Cancer Inst 97:30-39 